OPEN ACCESS

Edited by:

Simone Smala,

The University of Queensland,

Australia

Reviewed by:

Robyn M. Gillies,

The University of Queensland,

Australia

Vanessa A. Voellinger,

University of Giessen, Germany

*Correspondence: Rosa M. Pons rmpons@um.es

Specialty section:

This article was submitted to Educational Psychology,

a section of the journal

Frontiers in Education

Received: 28 April 2021 Accepted: 28 October 2021 Published: 12 November 2021

Citation:

Pons RM and Reyes V (2021) Exploring Reliability and Factorial Validity of Responsible Talk and its Impact on

Cooperative Classrooms.

Front. Educ. 6:702013.

doi: 10.3389/feduc.2021.702013

\section{Exploring Reliability and Factorial Validity of Responsible Talk and its Impact on Cooperative Classrooms}

\author{
Rosa M. Pons ${ }^{1 *}$ and Vicente Reyes ${ }^{2}$ \\ ${ }^{1}$ Department of Developmental and Educational Psychology, University of Murcia, Murcia, Spain, ${ }^{2}$ Centre for Research in \\ Educational Leadership and Management, University of Nottingham, Nottingham, United Kingdom
}

The aim of this study was to validate an instrument which enables the evaluation of talk which maximizes student performance during different segments of interactioninteractivity throughout a complete learning sequence. Based on works developed by the Learning and Research Development Center of the University of Pittsburgh, a scale was developed that gathered the most relevant behaviors of each proposed dimension by researchers from this university center. The scale was used to develop a core subject for a final year Bachelor of Arts degree in Primary Education at a university in Spain and was applied to the 65 students ( $M=19, F=46$ ) taking the subject. The data analysis used an exploratory factor analysis (EFA) that yielded a reliability of $\alpha=0.922$. EFA revealed a final interpretable three-factor structure, and the factorial solution comprised $87.86 \%$ of total variance. Results show that the talk that students use has three purposes: to constitute an effective group for learning, to build knowledge and to verify its acquisition. The results are discussed in terms of input from the Center for Research in Education and Educational Technologies at the Open University and the Learning Research and Development Center of the University of Pittsburgh.

Keywords: dialogic learning, exploratory factor analysis, accountable talk, higher education, cooperative learning

\section{INTRODUCTION}

For over 4 decades there has been "clear and convincing evidence that working in small groups (cooperative groups) can facilitate student performance, as well as more favorable attitudes towards peers and the subject" (Good et al., 1992, p. 167), which has been confirmed through numerous meta-analyzes carried out in that time (Gürdogan-Bayir and Bozkurt, 2018; Kyndt et al., 2013; Swanson et al., 2019). Nevertheless, we also know that the cooperative organization of the classroom for proper functioning, requires creating a certain context of interaction which does not usually occur. It is no surprise that numerous research highlights that the implementation of cooperative learning methods in the classroom faces different problems that condition its efficiency and effectiveness. More and more research points out that there are lack of awareness of the act of cooperating both by students and teachers, an unequal exchange of work among group members, inadequate organization of cooperative groups, insufficient support and monitoring by teachers before and during implementation of the action plan, etc. (Abdulahi et al., 2017). These problems could be found in two axes of interpretation: problems linked to teaching competence when implementing cooperative organization of the classroom and problems related to the interaction process itself among students at various moments of the learning sequence. 
As for teacher training, we know that teachers have an extremely heterogeneous conception of cooperative learning, its characteristics and operation in the classroom. A study carried out in Australia at the start of this decade shows that each teacher possesses different perceptions of cooperative learning and the factors that enable or inhibit its implementation (Hennessey and Dionigi, 2013). This way, one of the lines of research in this new generation of studies on cooperative learning deals with teaching competence, and scales are being developed that revolve around teachers' theoreticalpractical knowledge of the basic dimensions of cooperative learning: positive interdependence, face-to-face interaction, individual responsibility, interpersonal skills, group processing, group formation, etc. (Kocabas and Erbil, 2017).

Regarding peer interaction process, all studies underpin the fact that language conveys the communicative transactions that occur throughout the development of the learning sequences, before, during or after students performing their research, solving problems and reading or writing about content. Indeed, any dialogic learning system "is the result of the interactions produced in an egalitarian dialogue, which is oriented towards the acquisition of new knowledge, which basically depends on interaction with others, and which requires the maximization of the use of communication skills in any context" (Racionero and Valls, 2007, p. 548). It is true that research on cooperative learning suggests that group composition and task structure are important factors in determining the quality of learning by students however, since the pioneering work of Barnes and Todd (1977), all researchers stress the need to work on factors that affect discourse processes, regardless of whether the academic work takes place in a physical or virtual classroom (Cohen, 1994; Zimmermann et al., 2010). In this regard, the classroom and classroom talk has emerged as a critically important research agenda in the 21 st century.

Classroom talk which maximizes the effectiveness and efficiency of learning has been worked on from different nomenclatures, but with the same common denominator: accountable talk (Michaels et al., 2002), although we prefer the term responsible talk which better explains the reference to the complete sequence of the learning activity, exploratory talk (Mercer and Dawes, 2008) and transactive talk (Jurkowski and Hänze, 2015).

Accountable, exploratory, and transactional talk might be defined as specific types of social interactions in classrooms, both real and virtual, and which make up a type of speech where participants engage critically but constructively with the ideas of other classmates. offering relevant information for joint consideration, preparing proposals which can be challenged (as long as reasons are given and alternatives are offered) or reformulated. Its basis is the search for consensus and its essential features are the public nature of knowledge and visibility of reasoning during interaction.

Talk theorists try to learn how the different language dimensions (structural, functional, and behavioral) should be used to maximize the socio-cognitive benefit inherent in the process of peer interaction during the complete learning sequence: before, during and after the activity.
There appears to be a certain consensus that the first dimension should revolve around how to create a climate which favors interaction processes. The importance of the social climate of learning environments to maximize the sociocognitive effects of teaching and learning processes has been shown in several research and therefore counts on sufficient empirical evidence (Allodi, 2010). The classroom climate can be succinctly defined as "the intellectual, social, emotional and physical environment in which our students learn" (Ambrose et al., 2010, p. 170). Within this order of things, two possible latent variables should be considered: the most appropriate talk to generate a general climate of interaction and the talk necessary to establish a specific climate supporting the most effective procedural system to develop processes involved in acquiring knowledge.

However, an important current debate is the need for this climate to generate or not a safe structure in the classroom context. Indeed, although some researchers argue that the classroom ideal as a "safe space" is not only impossible but also unproductive (Sensoy and DiAngelo, 2014), even stating that feeling "unsafe" is an inevitable and necessary process to become critically and actively involved in society, other authors defend the importance of emotional security in the harmonious development of teaching and learning processes (Lowe, 2015). In this sense, Lowe's work appears to show that educational intervention must consider creating a classroom climate that generates positive learning experiences generating positive emotions, which does not always occur. One thing is to create a positive learning climate and quite another to create a climate of emotional safety. It seems convenient to include a third latent variable within the classroom climate dimension: adequate talk to bring about a climate of social and emotional safety in the student.

Therefore, when researchers develop the required talk determinants to generate a classroom climate maximizing the socio-cognitive effectiveness of the peer interaction process, it can be argued that three distinct latent variables emerge. The first referring to the general climate of the classroom, the second to the climate that fosters academic achievement and the third the climate that fosters a structure of emotional safety.

A second dimension to be contemplated refers to talk as a mediation instrument between content to be learned and students' cognitive structure. We can consider talk that is used for purely cognitive purposes, oriented to declarative and procedural knowledge, and talk presenting a clearly metacognitive goal oriented towards strategic and conditional knowledge. To address this dimension, a paradigmatic teaching and learning model of the B-D-A type (before-during-after) has been used covering the whole learning sequence (Weidner, 2018) since, for the theorists of this research topic (see for example, the works of the Institute for Learning of the University of Pittsburgh), accountable talk takes place during the development of a learning sequence, i.e., before, during or after the students carry out research, solve problems and read or write about content (Huss, 2007). In addition, there is sufficient empirical evidence of the value that the B-D-A teaching strategy places on performance, whatever content 
type and student academic level (Blömeke et al., 2019; Roberts et al., 2019). Ultimately, in this dimension we try to determine what is spoken and how it is spoken at each moment of the instructional sequence (when it is spoken), distinguishing between talk whose purpose is the construction of meanings (Moreira et al., 2019) and talk that enables the attribution of meaning to what has been learned (Ardasheva et al., 2016).

A recent review of the literature (Wolf et al., 2005; Ahamnn, 2017; Allen et al., 2018; Heyd-Metzuyanim et al., 2019) has enabled us to establish markers for analysis of these two types of talk. The indicators that appear most relevant refer to the use of information sources (including prior knowledge) and the establishment of their sufficiency or insufficiency, the manner in which they construct conjectures, formulate hypotheses and elaborate explanations, to the types of logical strategies used to present arguments and draw conclusions, to examples, analogies and hypothetical scenarios used and to structuring of arguments that allow us to focus and direct the topic and discussion.

Finally, a third dimension becomes essential when completing the circle for talk analysis in the classroom from the B-D-A paradigm: viewpoint assuming of responsibilities (Huss, 2007; Michaels et al., 2008), both individual and collective (Johnson and Johnson, 2003).

The interest of educational researchers in dialogic learning has given rise to several investigations that cover all educational levels, are multidisciplinary and have produced a rich and varied set of results that even transcend the teaching-learning instrumental relationship itself. Nevertheless, the works show a high degree of dispersion, not only from the legitimate perspective of the research questions posed, but from the aspects of dialogue on which they focus, type of evidence they provide and the way in which rigorous standards are constructed (Asterhan et al., 2020).

In this regard, theorists of talk in the classroom have tried to go beyond cognitive (Piaget) and sociocultural (Vigotsky) constructivisms and give the processes of "équilibration majorante" (how to learn) and the zone of proximal development (where one learns) a more concrete, comprehensive and effective instructional sense. Results show that peer-to-peer talk appears the key instrument for generating the most appropriate contradictions when it comes to achieving those cognitive regulations that are effective in constructing meanings and sense-making to learning. Furthermore, talk creates a space or zone of "intermental development" enabling participants to interact and develop their thinking together (Mercer, 2000).

From all the above, it can be deduced that studying the interaction processes that occur in the classroom requires detailed analysis of students' communicative transactions in order to determine whether their talk when interacting around learning content (interactivity) enables adequate flow of social, affective and cognitive exchanges.

The aim of this work is to establish observable and differentiable units in students' interactive talk both in the nuclear system (during) learning and in the peripheral system (before-after), starting from the three dimensions we have just analyzed: talk generating a positive learning context, talk establishing a significant mediation between the learning content and students' previous knowledge, and talk enabling a consolidation of the learning being carried out.

\section{METHODS}

\section{Participants}

The sample used was constituted by university students in their last year of the Primary Education degree. The students who formed part of the convenience sample belonged in the age range between 21 and 22 years. Students were enrolled in a compulsory subject on mathematical and literacy learning difficulties, specifically, the study was conducted in the section of mathematical learning difficulties (convenience sampling).

The sample size was 65 students $(M=19, F=46)$, which presented a symmetric distribution with respect to the results obtained in the prior knowledge test ( $x$ of 1.7 and $s$ of 0.14 ). There were no missing cases.

\section{Procedure}

The intervention began with an initial test on prior knowledge needed to tackle new content. This test consisted of 20 true-false questions, 10 on neuroscience concepts linked to calculus and 10 on cognitive psychology linked to the contents of the subject to be taught. The aim of this test was twofold. Firstly, to determine the initial schemes of the students and their level of development and, secondly, to be able to establish group composition, task structure and intra-group relationships that would be put in play (cooperation, collaboration, and tutoring). In short, how would we structure the equality parameter based on homogeneity/heterogeneity of the classroom.

The results of this test enabled us to determine what we would find faced with a group with little initial knowledge of the content to be dealt with $(\bar{x}=1.7)$ and with a high level of homogeneity $(s=$ 0.14 ). This led us to establish an approach in our inquiry in which collaborative practices were built on experiences of the participants. Previously, all the participants took part in disciplinary subject areas that utilized pedagogical techniques based on group work. These results led us to consider the use of introductory explanations in each of the three parts of the subject, to carry out a small reorganization of the materials and the inclusion of new elements (for example, explanatory videos) in order to make them potentially more significant and the option, almost mandatory, of using a high equality parameter in the formation of groups with a non-divisible task structure (collaboration relationship). Based on these data, the class was divided into 16 groups of 3-5 members.

Once groups were formed, students were informed that an intervention would be carried out by means of a cooperative organization of the classroom enabling to determine if the type of talk used in the interaction process influenced students' academic work. Permission was requested to use the data obtained completely anonymously.

As all the students had previous experience with group work, acquired during anterior courses, the professor gave the groups the freedom to determine their group functioning structure. In 
TABLE 1 | Features of accountable talk

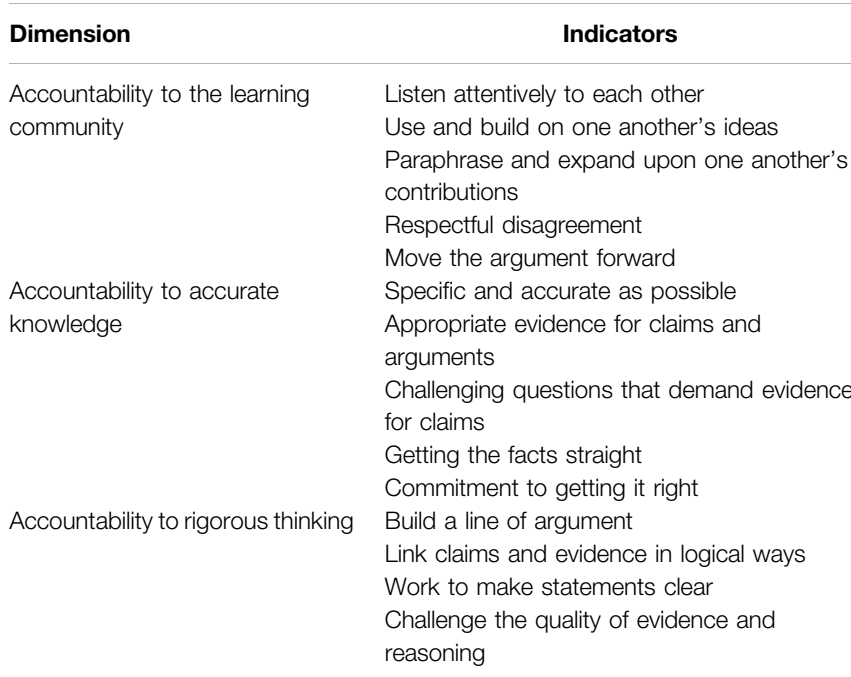

this sense, all groups used a role system and the roles in which there was agreement in every group was that of secretary and moderator. The responsibility of the latter was to organize and moderate the discussion sessions calling the team member by name. This made it possible for the unit of analysis to be the individual and also for us to identify through the audio recordings the contribution of each group member.

The first class was used to explain how activities would be developed, how talk should be used in the classroom (its elements, characteristics, etc.) and how students should function individually and in groups according to the task structure.

The content was divided into three parts, therefore, there were three three-hour lectures that located and focused the topic. After each topic, four three-hour sessions were developed addressing the content of the master lesson through a video and development portafolio which contains four or five files, discussion points and insights that the students use. The operation of groups was as follows: the first session was used to comment on the lesson, viewing and analyzing the video and planning the reading of documents, the second and third for analysis, comment and discussion of documents (which had been worked on individually at home) and the last session was relaxed where the aspects dealt with were discussed, at times tangentially, opinions were given on the authors of the documents, suitability of content for development of their future professional activity, etc.

All sessions were conducted in face-to-face learning and were recorded entirely in audio and sent to the professor (co-author of this work) through the Virtual Classroom.

Finally, the student's qualification consisted of an individual exam on all content.

\section{Instrument}

Studies performed by the Institute for Learning at the University of Pittsburgh (Michaels et al., 2010; 2016) reached the conclusion that accountable talk in the classroom may be determined by analyzing the student's linguistic behavior through a series of indicators that revolved around three dimensions (Table 1):

Based on these studies and supported by indicators prepared by the Learning and Research Development Center of the University of Pittsburgh (Junker et al., 2006; Wolf et al., 2006; Institute for Learning, 2011) we have made an adaptation in order to evaluate students' talk throughout all segments of interactivity that take place in a B-D-A teaching and learning process. The results of a refined analysis of behaviors proposed by the Center led us to develop a Responsible Speech Assessment Scale (ARTS) with 54 indicators, grouped around thirteen variables (Table 2).

The first 16 behaviors refer to what Michaels et al. (2016) call classroom environment. The following eight behaviors (from 17 to 24) are linked to what these authors call common language around accountable talk. Items 25 to 42 are behaviors linked to what they call classroom situations and, finally, the aforementioned authors dedicate a block of behaviors to responsibilities and roles, collected in the last 12 items (from 43 to 54). Each indicator was assessed by two co-authors, listening to the audios according to a summative, symmetric and equidistant Likert scale of four values, in which the score of each variable was the sum of those given to each of its indicators.

In relation to the codification process, each co-author evaluated all the indicators in each of the 65 participants. The co-authors engaged in productive discussions using their extensive exposure of working with groups and balancing this out with their experiences in making sensible judgments or what decision sciences describe as "decomposition and calculation" consistent with the seminal ideas of Tversy and Kahneman (2002), p. 44. The comparisons of the scores of the two raters determined 54 matrices that were, for the most part, diagonal matrices, so that the 54 calculated Cohen's Kappa values determined almost perfect concordances (Landis and Koch, 1977), with values between 0.91 (59/65) and 1 (65/65).

There is enough statistical evidence that, even with distortions in the perceived distances between scale points, Likert-type items behave closely on scales that are perceived as having equal intervals (Labovitz, 1967; Traylor, 1983). Thus, values obtained can be subjected to the procedures and parametric statistical tests that we perform below.

\section{Data Analysis}

Exploratory factor analysis (EFA) was implemented to determine the instrument validity by means of principal component analysis method.

The choice of this statistical technique is based on the fact that it tries to discover the internal structure of a large number of variables that have been used to analyze academic talk. The hypothesis from which we start is that there may be a series of factors associated with certain groups of these variables. In this situation, the EFA is the most appropriate technique. The objections that could be made to this technique due to the sample size do not rule out the use of this analysis since, in any case, "applying the EFA in an exploratory phase is preferable than rejecting it a priori” (De Winter et al., 2009, p. 171). More 
TABLE 2 | Behavioral scale.

\section{Variables}

Dialogic environment

Safety environment

Knowledge environment

Harness knowledge

Provide data

Acknowledge

Encapsulate

Build explications

Hypothesize

Accountable talk por reason

Data check

General accountable talk Roles

\section{Indicators}

Students' talk is appropriate to the purpose

Each student participates in all discussions

Three-quarters of classroom talk is by and among students

Students allow others to speak without interruption

Students listen actively to one another

Students indicate their level of agreement with the ideas that are expressed

Students feel safe to express their ideas

Students participate in all activities

Students speak on appropriate occasions

Students actively participate in classroom talk

Students make references to the interventions of other participants

Students test their own understanding of contents

Students redefine explanations

Students ask questions and propose examples to evaluate concepts and procedures

Students draw comparisons among ideas

Students identify their own bias

Students make reference to texts to support their arguments and assertions

Students make reference to knowledge built in the course of discussion

Examples used are appropriate

Claims made are questioned by participants

Request is made for factual information

Students call for the definition and clarification of terms under discussion

Students challenge whether the information being used is relevant

Students are able to identify if there is any prior knowledge that may be necessary to successfully tackle the topic

Students consult many sources of information

Students connect ideas between texts

Students use previous knowledge to support ideas and opinions

Students acknowledge that more information is needed

Students use sequential ideas to build logical and coherent arguments

Students use different kinds of data

Students use "what if" scenarios to ask for explanations

Students formulate hypotheses and suggest ways to investigate them

Students indicate when ideas need further support or explanation

Students use rational strategies to present arguments and draw conclusion

Students provide reasons for their claims and conclusions

Students use consistent arguments to draw conclusion from the premises

Students use "what if" scenarios to argue and support claims

Students divide topics to focus discussion

The soundness of the sources consulted to determine the quality of the premises-arguments-conclusion are assessed Assumptions used are always questioned

Students pose counterexamples and extreme case comparisons to challenge arguments and claims

Considering the above indicators, it could be said that the talk used by students is accountable talk

Students' body language is suitable

Speakers' comments are connected to previous ideas

Students avoid multiple conversations

Students' interest is in the whole discussion

Students elaborate and build upon ideas and each other's contributions

Talk remains related to text, subject, or issue

Related issues or topics are introduced and elaborated

Talk is about issues rather than participants

Students work toward the goal of clarifying or expanding a proposition

Students summarize, paraphrase each other's arguments

Students make an effort to ensure they understand one another

Students clarify or define terms under discussion importantly, we concur with McCallum et al.'s claims in which they assert that:

When communalities are consistently high (preferably all greater than 0.6), then that aspect of sampling that has a detrimental effect on model fit and precision of parameter estimates receives a low weight... Under such conditions, recovery of population factors can be very good under a range of levels of overdetermination and sample size. Good recovery of population factors can be achieved with samples that would traditionally be considered too 
TABLE 3 | KMO measure and Bartlett's test.

\begin{tabular}{llc}
\hline $\begin{array}{l}\text { KMO measure of } \\
\text { sampling adequacy }\end{array}$ & \multicolumn{2}{c}{$\mathbf{0 . 6 7 6}$} \\
\hline Bartlett's test of sphericity & Approx. Chi-Squared & \\
& gl & $1,509,924$ \\
& Sig. & 78 \\
& & 0.000
\end{tabular}

TABLE 4 | Correlation matrix.

\begin{tabular}{lcc}
\hline & Total & Sig. \\
\hline Dialogic environment & $0.713^{\star \star}$ & 0.000 \\
Knowledge environment & $0.939^{\star \star}$ & 0.000 \\
Safety environment & $0.900^{\star \star}$ & 0.000 \\
Harness knowledge & $0.819^{\star \star}$ & 0.000 \\
Provide data & $0.893^{\star \star}$ & 0.000 \\
Acknowledge & $0.877^{\star \star}$ & 0.000 \\
Encapsulate & $0.829^{\star \star}$ & 0.000 \\
Build explications & $0.928^{\star \star}$ & 0.000 \\
Hypothesize & $0.790^{\star \star}$ & 0.000 \\
Accountable reason & $0.938^{\star \star}$ & 0.000 \\
Data check & $0.720^{\star \star}$ & 0.000 \\
General accountable talk & $0.780^{\star \star}$ & 0.000 \\
Roles & $0.955^{\star \star}$ & 0.000
\end{tabular}

${ }^{* *} p<0.01$

small for factor analytic studies, even when $\mathrm{N}$ is well below 100 (McCallum et al., 1999, p. 96).

In our study, our commonalities (see Table 6) are way above 0.6 , which gives us confidence -- consistent with McCallum et al.'s claims --about the robust nature of the results of our factor analysis. This is also consistent with Hair et al. (2010) who maintains that an EFA is perfectly acceptable when the sample size is made up of more than 50 cases.

Values for Kaiser-Meyer-Olkin (KMO) measure of sampling adequacy and Bartlett's test of sphericity were used to assess the suitability of data for factorization. In addition, the principal component analysis was performed with Varimax rotation to facilitate interpretation of the factors. Finally, internal consistency was assessed by means of Crombach's alpha coefficient. All analyses were performed using SPSS, version 21.

\section{RESULTS}

To determine the feasibility of the factor analysis, the KMO index was calculated and the Bartlett's sphericity test was performed (Table 3).

Results indicated that the sample and the data matrix were adequate to perform the factor analysis (KMO $>0.6$ and $\left.x_{78}^{2}<0.05\right)$. Additionally, the correlation matrix results show significant values close to 1 , justifying the rest of our analyzes (Table 4).

The scale ( $\mu=186.15$ and $\sigma=19.75)$ presents an "excellent" (George and Mallery, 2003, p. 231) internal consistency coefficient (Cronbach's $\alpha$ revealed a value of 0.922 ).

All item-total correlations (homogeneity index) were high for all items as there are no correlations lower than 0.2 , therefore none of the elements of the scale should be discarded or
TABLE 5 | Item-total correlation.

\begin{tabular}{lcc}
\hline & $\begin{array}{c}\text { Corrected } \\
\text { item-total correlation }\end{array}$ & $\begin{array}{c}\text { Cronbach's alpha if } \\
\text { item deleted }\end{array}$ \\
\hline Harness knowledge & 0.804 & 0.918 \\
Provide data & 0.873 & 0.913 \\
Acknowledge & 0.863 & 0.917 \\
Encapsulate & 0.818 & 0.919 \\
Build explications & 0.924 & 0.911 \\
Hypothesize & 0.763 & 0.917 \\
Accountable reason & 0.917 & 0.905 \\
Data check & 0.691 & 0.917 \\
General accountable talk & 0.769 & 0.921 \\
Roles & 0.944 & 0.903 \\
Dialogic environment & 0.689 & 0.921 \\
Knowledge environment & 0.891 & 0.939 \\
Safety environment & 0.871 & 0.907
\end{tabular}

TABLE 6 | Communalities.

\begin{tabular}{lcc}
\hline & Initial & Extraction \\
\hline Dialogic environment & 1.000 & 0.816 \\
Knowledge environment & 1.000 & 0.948 \\
Safety environment & 1.000 & 0.881 \\
Harness knowledge & 1.000 & 0.934 \\
Provide data & 1.000 & 0.932 \\
Acknowledge & 1.000 & 0.914 \\
Encapsulate & 1.000 & 0.760 \\
Build explications & 1.000 & 0.946 \\
Hypothesize & 1.000 & 0.785 \\
Accountable reason & 1.000 & 0.915 \\
Data check & 1.000 & 0.841 \\
General accountable talk & 1.000 & 0.803 \\
Roles & 1.000 & 0.947
\end{tabular}

Extraction method: Principal components analysis.

reformulated, and they can also be combined with each other to obtain a total score (Table 5).

The exploratory factor analysis performed using the principal component analysis with Varimax rotation, allowed us to establish communalities of variables (Table 6), enabling us to conclude that all are explained by the model since none presents a percentage of explained variance lower than $75 \%$.

Starting from our original hypothesis, we decided to obtain three factors, which should present an adequate psychological explanation of the interaction process (Table 7), determining the variables that correlate with each factor obtained.

Although as observed in the previous table (Table 7), eigenvalues show the existence of two factors (eigenvalues greater than 1), which cumulatively explain a variance close to $82 \%$ (74 and $8 \%$, respectively), we chose to resort to the extraction of three factors for two reasons. Firstly, to try to verify the general aim of this work (existence of three types of talk) and, secondly, if we wished to use these data for further studies, we should find a percentage of explained variance in the region of $90 \%$ and the introduction of a third factor would bring us closer to this value (87.9\%).

The matrix of rotated components (Table 8) determines the factorial structure of the scale, taking load's values greater than 0.7 . 
TABLE 7 | Total variance explained.

\begin{tabular}{|c|c|c|c|c|c|c|c|c|c|}
\hline \multirow[t]{2}{*}{ Components } & \multicolumn{3}{|c|}{ Initial eigenvalues } & \multicolumn{3}{|c|}{ Extraction sums of squared loadings } & \multicolumn{3}{|c|}{ Rotation sums of squared loadings } \\
\hline & Total & $\begin{array}{c}\% \text { of } \\
\text { variance }\end{array}$ & Cumulative \% & Total & $\begin{array}{c}\% \text { of } \\
\text { variance }\end{array}$ & Cumulative \% & Total & $\begin{array}{c}\% \text { of } \\
\text { variance }\end{array}$ & Cumulative \% \\
\hline 1 & 9,615 & 73,963 & 73,963 & 9,615 & 73,963 & 73,963 & 4,543 & 34,943 & 34,943 \\
\hline 2 & 1,029 & 7.916 & 81.879 & 1.029 & 7.916 & 81.879 & 3.616 & 27.817 & 62.759 \\
\hline 3 & 0.777 & 5.979 & 87.858 & 0.777 & 5.979 & 87.858 & 3.263 & 25.099 & 87.858 \\
\hline 4 & 0.605 & 4.653 & 92.511 & - & - & - & - & - & - \\
\hline 5 & 0.349 & 2.688 & 95.198 & - & - & - & - & - & - \\
\hline 6 & 0.282 & 2.168 & 97.367 & - & - & - & - & - & - \\
\hline 7 & 0.144 & 1.108 & 98.475 & - & - & - & - & - & - \\
\hline 8 & 0.067 & 0.517 & 98.992 & - & - & - & - & - & - \\
\hline 9 & 0.054 & 0.416 & 99.408 & - & - & - & - & - & - \\
\hline 10 & 0.039 & 0.302 & 99.710 & - & - & - & - & - & - \\
\hline 11 & 0.025 & 0.191 & 99.901 & - & - & - & - & - & - \\
\hline 12 & 0.010 & 0.075 & 99.976 & - & - & - & - & - & - \\
\hline 13 & 0.003 & 0.024 & 100.000 & - & - & - & - & - & - \\
\hline
\end{tabular}

Extraction method: Principal components analysis.

TABLE 8 | Rotated component matrix .

\begin{tabular}{lccc}
\hline & \multicolumn{3}{c}{ Components } \\
\cline { 2 - 4 } & $\mathbf{1}$ & $\mathbf{2}$ & $\mathbf{3}$ \\
\hline Dialogic environment & $\mathbf{0 . 8 4 7}$ & 0.110 & 0.292 \\
Hypothesize & $\mathbf{0 . 7 8 3}$ & 0.370 & 0.189 \\
Safety environment & $\mathbf{0 . 7 6 4}$ & 0.482 & 0.254 \\
Accountable reason & $\mathbf{0 . 7 5 0}$ & 0.388 & 0.449 \\
Provide data & $\mathbf{0 . 7 2 9}$ & 0.229 & 0.591 \\
Encapsulate & $\mathbf{0 . 7 1 3}$ & 0.371 & 0.337 \\
Data check & 0.204 & $\mathbf{0 . 8 6 9}$ & 0.210 \\
General accountable talk & 0.265 & $\mathbf{0 . 7 7 9}$ & 0.355 \\
Build explications & 0.490 & $\mathbf{0 . 7 4 7}$ & 0.384 \\
Roles & 0.539 & $\mathbf{0 . 7 0 0}$ & 0.408 \\
Harness knowledge & 0.301 & 0.312 & $\mathbf{0 . 8 6 3}$ \\
Acknowledge & 0.402 & 0.331 & $\mathbf{0 . 8 0 2}$ \\
Knowledge environment & 0.364 & 0.525 & $\mathbf{0 . 7 3 5}$
\end{tabular}

Extraction method: Principal components analysis.

Rotation method: Varimax with Kaisser normalization.

${ }^{a}$ Rotation converged in 6 iterations.

This table enables us to see that the factorial solution of our work confirms a first factor including those behaviors that generate a positive climate for the development of an interactive system. This positive climate means everyone can participate in all activities, eliminating any type of socio-cognitive barrier that hinders the expression of ideas and feelings. All this allows hypotheses to flow and a rich system of heuristics to be developed for verification or refutation, endorsed by an alternating analysis and synthesis process which enriches the inductive and deductive reasoning of group members. Variables included are: dialogic environment, formulating of conjectures and hypotheses (hypothesize), safety environment, accountable talk for reasoning (accountable talk reason), providing data on their claims and arguments (provide data) and synthesizing of various of information sources (encapsulate) which we refer to as involvement in talk.

The second factor comprises behaviors that allow group debate to be constructive and enable interpretation of new content based on previous knowledge and the teacher's contributions. This kind of talk allows an orientation of learning towards the search for complementary information, logically ordering available information to provide the most correct answer to each question (convergent thinking) and generating ideas by exploring possible solutions (divergent thinking). In the development of this process, group roles and their alternation play a decisive role. The variables that configure this factor are: questioning the quality of data and reasoning of other participants (data check), classroom talk is accountable to levels of evidence (general accountable talk), build explanations and roles. We have called this factor talk to know.

Finally, the third factor contains behaviors in which understanding is tested, explanations are changed, ideas are compared, explicit reference is given to the knowledge acquired, and the sources that have made it possible to acquire are valued. The variables embedded in this factor are: use specific and accurate knowledge (harness knowledge), identify knowledge that might not yet be available and is necessary to successfully address issue (acknowledge) and knowledge environment. We have called this factor talk of consolidation.

These three factors contain all the talk behaviors produced by the students throughout the learning sequence (B-D-A).

\section{DISCUSSION}

Talk has been the instrument on which the efforts of researchers have focused to demonstrate the effectiveness of dialogical teaching and learning processes, that is, those processes focused on "teaching and learning through, for and as dialogue" (Kim and Wilkinson, 2019, p. 70).

In this order of things we could admit roughly explicit agreement among the various authors who develop their work on cooperative and/or dialogic learning, that the research proceeding from the Center for Research in Education and Educational Technologies of the Open University and the University of Cambridge, under the direction of Mercer and Littleton (2007), Littleton and Mercer (2013), and the Learning 
Research and Development Center of the University of Pittsburgh, led by Resnick et al. (2015), Clarke et al. (2018) since the end of the last century have been setting guidelines on how to use talk in the classroom.

Although there are different approaches to dialogic teaching (Rapanta et al., 2021), all authors agree that dialogic learning must be first and foremost, evaluable (Alexander, 2008). For this reason, various scholars of the Learning Research and Development Center have been making a giant effort to provide instruments (Wolf et al., 2006; Junker et al., 2006) enabling unify the disparity of results frequently reported (Asterhan, et al., 2020). In addition to these aforesaid works, some of Merces's collaborators and, notably, Lauren Resnick's collaborators, are developing talk assessment tools that are beginning to be used in recent research on dialogic learning, such as that by a group of researchers from the Universities of Barcelona (Spain) and Lisbon (Portugal) under the auspices of the European Union Research and Innovation Action Program (Project number 77045).

These instruments for evaluating talk during dialogic learning, in spite of being attempts that present a more than adequate level of utility to analyze student interactions are especially nonspecific, such as the Low Inference Discourse Observation (LIDO) by O'Connor and LaRusso (2014) that uses five measures for learning (interpellations between peers, reference to the intervention of other peers, argumentation, statements with complete ideas and answers with a minimal statement) or too ambitious, which include an almost exhaustive number of behaviors that achieve figures close to a hundred (some reference). Moreover, all focus almost exclusively on the "during" section of learning.

To establish an intermediate solution enabling us to understand which behaviors are relevant to analysis, from all these works we elaborated a set of indicators that would allow us to know which behaviors are relevant for learning throughout the entire interactive sequence (B-D-A).

The results which are reflected in the scale we present appear to indicate that, given the high homogeneity index, the variables included in the study are all relevant, although given the variance found, there is a part of the variance that the scale does not explain, so it would be necessary to look for other variables that should be assigned to the process. However, we consider it to be a very useful initial instrument for evaluating peer interaction throughout the entire interactive sequence, as well as for several reasons interpreting the effects of these interactions on the act of learning. Firstly, for the reason that during the entire intervention the most basic rules of dialogic learning were respected and the interaction-interactivity processes were performed spontaneously and intentionally and from an egalitarian dialogue that led to a learning of the subject performed on the basis of consensus (Bakker et al., 2015). Second, it was observed that the search for consensus obliged the students, almost continuously, to maximize their cognitive abilities and to develop a reflective and critical participation of content consistent with results by Nussbaum and Asterhan (2016) on the fact that participation structures in argumentation strengthen the development of proactive executive control strategies and therefore an improvement in fluid intelligence (Taatgen, 2013). Third, in dialogic relationships, students contributed their prior knowledge and individual skills, with the common goal of assimilating the content through shared agreements and collectively creating high-level learning processes by means of caring interactions. The result is learning with a deeper instrumental dimension and having deep meaning due to the characteristics of the highly interactive learning process (Simpson, 2016).

The respect shown throughout the implementation of the experience, to the basic structures of dialogic learning developed on the basis of cooperative groups, allows us to harbor many hopes that this instrument can contribute to bringing a change in pedagogical culture in schools and, as Lauren B. Resnick demands for the next generation of studies on dialogic learning, be an element of help "for maintaining the commitment to scientific standards of evidence and, at the same time, evaluating and disseminating, the difficult work that teachers perform" (Resnick et al., 2018, p.335).

In view of the above, no one doubts the importance of peer interaction in the process of knowledge construction. However, although most of the studies conducted to date confirm this hypothesis, not all interactive processes have the same impact on learning, as shown by the size of the effects of the different investigations carried out over the last half century. The explanation to these differences is usually based on the quality of the interaction process and, in this sense, the different studies point to the quality and quantity of the communicative exchanges, so that it is necessary to have a tool that makes it possible to analyze them. This work affords a first diagnostic tool to provide a measurement system to the works that try to establish a causal relationship between the kinds of interaction in the classroom and the academic performance of the students. We emphasize the idea of initial instrument for several reasons that constrain this work. First, the population to which it refers (university students with experience in group work and assigned to a specific discipline) generates a great bias; secondly, the sample size and finally, the amount of variance explained that could be improved if the data collection instrument (audio) provided more information to the communication analysis process (video). Despite all this, we believe that this instrument will allow us to deepen the analysis of interaction processes in the classroom and initiate a series of cross-sectional studies that are of enormous relevance for instruction (interactive variations with age, influence of content, etc.).

\section{DATA AVAILABILITY STATEMENT}

The raw data supporting the conclusions of this article will be made available by the authors, without undue reservation.

\section{ETHICS STATEMENT}

Ethical review and approval was not required for the study on human participants in accordance with the local legislation and institutional requirements. The patients/participants provided their written informed consent to participate in this study.

\section{AUTHOR CONTRIBUTIONS}

All authors listed have made a substantial, direct, and intellectual contribution to the work and approved it for publication. 


\section{REFERENCES}

Abdulahi, M. M., Hashim, H., and Kawo, M. (2017). Improving the Achievement of Second Year Natural Resource Management Students of Madawalabu University through Cooperative Learning. Educ. Res. Rev. 12 (6), 356-365. doi:10.5897/ERR2016.2918

Ahmann, C. (2017). Accountable Talk: "Real" Conversations in Baltimore City Schools. Anthropol. Educ. Q. 48 (1), 77-97. doi:10.1111/aeq.12184

Alexander, R. J. (2008). Towards Dialogic Teaching: Rethinking Classroom Talk. 4th edition. Cambridge, United Kingdom: Dialogos.

Allen, D., Blythe, T., Dichter, A., and Lynch, T. (2018). Protocols in the Classroom: Tools to Help Students Read, Write, Think, and Collaborate. New York, NY: Teachers College Press.

Allodi, M. W. (2010). The Meaning of Social Climate of Learning Environments: Some Reasons Why We Do Not Care Enough about it. Learn. Environ Res. 13 (2), 89-104. doi:10.1007/s10984-010-9072-9

Ambrose, S. A., Bridges, M. W., DiPietro, M., Lovett, M. C., and Norman, M. K. (2010). How Learning Works: Seven Research-Based Principles for Smart Teaching. San Francisco, CA: Jossey-Bass.

Ardasheva, Y., Howell, P. B., and Vidrio Magaña, M. (2016). Accessing the Classroom Discourse Community through Accountable Talk: English Learners' Voices. Tesol Q. 7 (3), 667-699. doi:10.1002/tesj.237

Asterhan, C. S. C., Howe, C., Lefstein, A., Matusov, E., and Reznitskaya, A. (2020). Controversies and Consensus in Research on Dialogic Teaching and Learning. Dialogic Pedagogy J. 8, S1-S16. doi:10.5195/dpj.2020.312

Bakker, A., Smit, J., and Wegerif, R. (2015). Scaffolding and Dialogic Teaching in Mathematics Education: Introduction and Review. ZDM Maths. Educ. 47 (7), 1047-1065. doi:10.1007/s11858-015-0738-8

Barnes, D., and Todd, F. (1977). Communication and Learning in Small Groups. London, United Kingdom: Routledge \& Kegan Paul Ltd. doi:10.4135/ 9781446279526

Blömeke, S., Thiel, O., and Jenßen, L. (2019). Before, during, and after Examination: Development of Prospective Preschool Teachers' Mathematics-Related Enjoyment and Self-Efficacy. Scand. J. Educ. Res. 63 (4), 506-519. doi:10.1080/00313831.2017.1402368

Clarke, S. N., Resnick, L. B., and Rosé, C. P. (2018). "Discourse Analytics for Classroom Learning," in Learning Analytics in Education. Editors D. Niemi, R. D. Pea, B. Saxberg, and R. E. Clark (Charlotte, NC: IAP Inc), 139-153.

Cohen, A. D. (1994). Assessing Language Ability in the Classroom. 2nd ed. Boston, MA: Heinle \& Heinle.

De Winter, J. C. F., Dodou, D., and Wieringa, P. A. (2009). Exploratory Factor Analysis with Small Sample Sizes. Multivariate Behav. Res. 44, 147-181. doi:10.1080/00273170902794206

George, D., and Mallery, P. (2003). SPSS for Windows Step by Step: A Simple Guide and Reference. 4th ed.. Boston, MA: Allyn \& Bacon.

Good, T. L., Mulryan, C., and McCaslin, M. (1992). "Grouping for Instruction in Mathematics: A Call for Programmatic Research on Small-Group Processes," in Handbook of Research on Mathematics Teaching and Learning. Editor D. A. Grouws (Boston, MA: MacMillan Publishing Co), 165-196.

Gürdogan-Bayir, Ö., and Bozkurt, M. (2018). Effectiveness of Cooperative Learning Approaches Used in the Course of Social Studies in Turkey: A Meta-Analysis Study. Eur. J. Educ. Stud. 4 (10), 171-192. doi:10.5281/ zenodo.131386

Hair, J. F., Black, W. C., Babin, B. J., and Anderson, R. E. (2010). Multivariate Data Analysis. 7th ed. Englewood Cliffs, NJ: Prentice-Hall.

Hennessey, A., and Dionigi, R. A. (2013). Implementing Cooperative Learning in Australian Primary Schools: Generalist Teachers' Perspectives. Issues Educ. Res. 23 (1), 52-68. http://www.iier.org.au/iier23/2013conts.html.

Heyd-Metzuyanim, E., Smith, M., Bill, V., and Resnick, L. B. (2019). From Ritual to Explorative Participation in Discourse-Rich Instructional Practices: A Case Study of Teacher Learning through Professional Development. Educ. Stud. Math. 101 (2), 273-289. doi:10.1007/s10649-018-9849-9

Huss, J. A. (2007). Let's Talk about Talking: Accountable Talk and Participatory Learning. Middle Ground 11 (1), 28-29. https://eric.ed.gov/?id=ED497642.

Institute for Learning (2011). Accountable Talk Practices. Institute for Learning, University of Pittsburgh. Available at: https://ifl.pitt.edu/documents/AT FandI_080613.pdf. (Accessed November 5, 2021).
Johnson, D. W., and Johnson, R. T. (2003). Assessing Students in Groups: Promoting Group Responsibility and Individual Accountability. Thousand Oaks, CA: Corwin Press.

Junker, B., Weisberg, Y., Matsumura, L. C., Crosson, A., Wolf, M. K., Levison, A., et al. (2006). Overview of the Instructional Quality Assessment. CSE Technical Report 671. Los Angeles, CA: University of California, National Center for Research on Evaluation, Standards, and Student Testing. Available at: https:// cresst.org/wp-content/uploads/R671.pdf. (Accessed November 5, 2021).

Jurkowski, S., and Hänze, M. (2015). How to Increase the Benefits of Cooperation: Effects of Training in Transactive Communication on Cooperative Learning. Br. J. Educ. Psychol. 85 (3), 357-371. doi:10.1111/bjep.12077

Kim, M.-Y., and Wilkinson, I. A. G. (2019). What Is Dialogic Teaching? Constructing, Deconstructing, and Reconstructing a Pedagogy of Classroom Talk. Learn. Cult. Soc. Interaction 21, 70-86. doi:10.1016/j.lcsi.2019.02.003

Kocabas, A., and Gokce Erbil, D. (2017). A Scale Development for Teacher Competencies on Cooperative Learning Method. UJER 5 (3), 316-324. doi:10.13189/ujer.2017.050303

Kyndt, E., Raes, E., Lismont, B., Timmers, F., Cascallar, E., and Dochy, F. (2013). A Meta-Analysis of the Effects of Face-To-Face Cooperative Learning. Do Recent Studies Falsify or Verify Earlier Findings? Educ. Res. Rev. 10, 133-149. doi:10.1016/j.edurev.2013.02.002

Labovitz, S. (1967). Some Observations on Measurement and Statistics. Social Forces 46 (2), 151-160. doi:10.2307/2574595

Landis, J. R., and Koch, G. G. (1977). The Measurement of Observer Agreement for Categorical Data. Biometrics 33 (1), 159-174. doi:10.2307/2529310

Littleton, K., and Mercer, N. (2013). Interthinking: Putting Talk to Work. Abingdon, Oxon: Routledge. doi:10.4324/9780203809433

Lowe, P. (2015). Lessening Sensitivity: Student Experiences of Teaching and Learning Sensitive Issues. Teach. Higher Educ. 20 (1), 119-129. doi:10.1080/ 13562517.2014.957272

MacCallum, R. C., Widaman, K. F., Zhang, S., and Hong, S. (1999). Sample Size in Factor Analysis. Psychol. Methods 4 (1), 84-99. doi:10.1037/1082-989x.4.1.84

Mercer, N., and Dawes, L. (2008). "The Value of Exploratory Talk," in Exploring Talk in School: Inspired by the Work of Douglas Barnes. Editors N. Mercer and S. Hodgkinson (Thousand Oaks, CA: Sage), 55-72.

Mercer, N., and Littleton, K. (2007). Dialogue and the Development of Children's Thinking: A Sociocultural Approach. Abingdon, Oxon: Routledge.

Mercer, N. (2000). Words \& Minds: How We Use Language to Think Together. Abingdon, Oxon: Routledge.

Michaels, S., O' Connor, M. C., Hall, M. W., and Resnick, L. B. (2016). Accountable Talk Sourcebook ${ }^{\circledR}$ : For Classroom Conversation that Works. Institute for Learning, University of Pittsburgh. Available at: https://ifl.pitt.edu/ documents/AT-SOURCEBOOK2016.pdf. (Accessed November 5, 2021).

Michaels, S., O'Connor, C., Hall, M. W., and Resnick, L. (2002). Accountable Talk: Classroom Conversation that Works. Pittsburgh, PA: Institute for Learning, University of Pittsburgh. (Accessed November 5, 2021).

Michaels, S., O'Connor, C., and Resnick, L. B. (2008). Deliberative Discourse Idealized and Realized: Accountable Talk in the Classroom and in Civic Life. Stud. Philos. Educ. 27 (4), 283-297. doi:10.1007/s11217-007-9071-1

Michaels, S., O'Connor, M. C., Hall, M. W., and Resnick, L. B. (2010). Accountable Talk $^{\circledR}$ Sourcebook: For Classroom Conversation that Works. Version 3.1. Institute for Learning, University of Pittsburgh. Available at: https://ifl.pitt. edu/educator-resources/publications.cshtml. (Accessed November 5, 2021).

Moreira, P., Marzabal, A., and Talanquer, V. (2019). Investigating the Effect of Teacher Mediation on Student Expressed Reasoning. Chem. Educ. Res. Pract. 20 (3), 606-617. doi:10.1039/c9rp00075e

Nussbaum, E. M., and Asterhan, C. S. C. (2016). "The Psychology of far Transfer From Classroom Argumentation," The psychology of Argument: Cognitive Approaches to Argumentation and Persuasion. Editors L. Bonelli, F. Paglieri, and S. Felletti. (London: College Publications), 407-423. doi:10.1039/ c9rp00075e

O'Connor, C., and LaRusso, M. (2014). "Working with a Low-Inference Discourse Observation Tool: What Can We See," in The meeting of Annual Educational Research Association (Philadelphia, PA), Available at: https://www.aera.net/EventsMeetings/Annual-Meeting/Previous-Annual-Meetings/2014-Annual-Meeting. (Accessed April 3-7, 2014).

Racionero, S., and Valls, R. (2007). "Dialogic Learning. A Communicative Approach to Teaching and Learning," in The Praeger Handbook of 
Education and Psychology. Editors J. Kincheloe and R. Horn (Westport, CT: Greenwood Publishers), Vol. 3, 548-557.

Rapanta, C., Garcia-Mila, M., Remesal, A., and Gonçalves, C. (2021). The Challenge of Inclusive Dialogic Teaching in Public Secondary School. Comunicar: Media Educ. Res. J. 29 (66), 21-31. doi:10.3916/c66-2021-02

Resnick, L. B., Asterhan, C. S. C., Clarke, S. N., and Schantz, F. (2018). "Next Generation Research in Dialogic Learning," in Wiley Handbook of Teaching and Learning. Editors G. E. Hall, L. F. Quinn, and D. M. Gollnick (Hoboken, NJ: Wiley-Blackwell), 323-338. doi:10.1002/9781118955901.ch13

Resnick, L. B., Asterhan, C. S. C., and Clarke, S. N. (2015). "Talk, Learning, and Teaching," in Socializing Intelligence through Academic Talk and Dialogue. Editors L. B. Resnick, C. A. Asterhan, and S. N. Clarke (Washington, DC: American Educational Research Association), 1-12. doi:10.3102/978-0935302-43-1_1

Roberts, C. A., Kim, S., Tandy, J., and Meyer, N. (2019). Using Content Area Literacy Strategies during Shared Reading to Increase Comprehension of High School Students with Moderate Intellectual Disability on Adapted Science Text. Education Train. Autism Develop. Disabilities 54 (2), 147-160. http://www. daddcec.com/uploads/2/5/2/0/2520220/etadd_june_54_2_2019.pdf\#page $=46$.

Sensoy, Ö., and DiAngelo, R. (2014). Respect Differences? Challenging the Common Guidelines in Social justice Education. Democracy Educ. 22 (2), 1-10. https://democracyeducationjournal.org/home/vol22/iss $2 / 1$.

Simpson, A. (2016). Designing Pedagogic Strategies for Dialogic Learning in Higher Education. Technol. Pedagogy Educ. 25 (2), 135-151. doi:10.1080/ 1475939X.2015.1038580

Swanson, E., McCulley, L. V., Osman, D. J., Scammacca Lewis, N., and Solis, M. (2019). The Effect of Team-Based Learning on Content Knowledge: A MetaAnalysis. Active Learn. Higher Educ. 20 (1), 39-50. doi:10.1177/ 1469787417731201

Taatgen, N. A. (2013). The Nature and Transfer of Cognitive Skills. Psychol. Rev. 120 (3), 439-471. doi:10.1037/a0033138

Traylor, M. (1983). Ordinal and Interval Scaling. J. Market Res. Soc. 25 (4), 297-303.

Tversky, A., and Kahneman, D. (2002). "Extensional versus Intuitive Reasoning," in Heuristics and Biases: The Psychology of Intuitive Judgment. Editors
T. Gilovich, D. Griffin, and D. Kahneman (Cambridge, United Kingdom: Cambridge University Press), 19-48. doi:10.1017/cbo9780511808098.003

Weidner, B. N. (2018). Content Area Literacy in Ensemble Music Education: The Before-During-After Instructional Framework. J. Music Teach. Educ. 27 (3), 114-127. doi:10.1177/1057083717732512

Wolf, M. K., Crosson, A. C., and Resnick, L. B. (2005). Classroom Talk for Rigorous reading Comprehension Instruction. Reading Psychol. 26 (1), 27-53. doi:10.1080/02702710490897518

Wolf, M. K., Crosson, M. C., and Resnick, L. B. (2006). Accountable Talk in Reading Comprehension Instruction. CSE Technical Report 670. Los Angeles, CA: University of California, National Center for Research on Evaluation, Standards, and Student Testing. Available at: https://eric.ed.gov/?id=ED492865. (Accessed November 5, 2021).

Zimmermann, T., Bucher, K. L., and Hurtado, D. (2010). "Hybrid Dialog: Dialogic Learning in Large Lecture Classes," in Learning Management System Technologies and Software Solutions for Online Teaching: Tools and Applications. Editor Y. Kats (Hershey, PA: Information Science Reference, IGI Global), 314-331. Available at: https://www.igi-global.com/gateway/chapter/43460.

Conflict of Interest: The authors declare that the research was conducted in the absence of any commercial or financial relationships that could be construed as a potential conflict of interest.

Publisher's Note: All claims expressed in this article are solely those of the authors and do not necessarily represent those of their affiliated organizations, or those of the publisher, the editors and the reviewers. Any product that may be evaluated in this article, or claim that may be made by its manufacturer, is not guaranteed or endorsed by the publisher.

Copyright $(2021$ Pons and Reyes. This is an open-access article distributed under the terms of the Creative Commons Attribution License (CC BY). The use, distribution or reproduction in other forums is permitted, provided the original author(s) and the copyright owner(s) are credited and that the original publication in this journal is cited, in accordance with accepted academic practice. No use, distribution or reproduction is permitted which does not comply with these terms. 